\title{
"Who am I to bring diversity into the classroom?" Learning communities wrestle with creating inclusive college classrooms
}

\author{
Jennifer R. Considine ${ }^{1}$, Jennifer E. Mihalick², Yoko R. Mogi-Hein ${ }^{3}$, Marguerite W. Penick- \\ Parks $^{4}$, and Paul M. Van Auken ${ }^{5}$
}

\begin{abstract}
This study explored the experiences of gateway course instructors during the implementation of pedagogical changes aimed at improving the success of diverse students. A detailed case study was built through analysis of peer observations, focus groups, oral and written reflections, student grades, indepth interviews, and pre and post student surveys. Results showed that instructors faced three major challenges in implementing pedagogical changes: pragmatic challenges, student-centered challenges, and challenges to instructor self-concept. Embracing a learning paradigm and participating in a learning community helped instructors to manage these challenges as they worked to create more inclusive learning environments for students.
\end{abstract}

Keywords: diversity, inclusive pedagogy, learning communities, reflective practitioner, culturally responsive pedagogy

This study is the outgrowth of a faculty development effort by our university to increase the use of learner-centered, culturally responsive pedagogies by instructors on our campus. Gay (2000) defines culturally responsive teaching as using the cultural knowledge, prior experiences, and performance styles of diverse students to make learning more appropriate and effective for them; it teaches to and through the strengths of these students. The ultimate goal of the faculty development effort was to improve the academic success and retention rates among firstgeneration and minority college students who, on our campus and others, have historically encountered greater challenges in completing their degrees (Cooper, 2010).

In this case study, we describe one intervention, a Gateway Success workshop designed to increase the use of these teaching strategies, and explore the experiences of instructors working to change their courses. Exploring this issue led not only to the discovery of several common challenges, but also to the finding that learning communities seemed to help instructors to manage these challenges.

\section{Literature Review}

Previous research suggests that culturally responsive pedagogies can improve outcomes for all students, but especially for students in these high-risk groups (Nelson, 1996; Richards, Brown, \& Forde, 2007; Steele, 2010); however, these strategies are not widely used (Sleeter, 2012). If higher education is to increase the use of culturally responsive pedagogy and other research based instructional strategies in higher education, there must be a greater understanding

\footnotetext{
${ }^{1}$ University of Wisconsin-Oshkosh, Department of Communication, considij@uwosh.edu

${ }^{2}$ University of Wisconsin-Oshkosh, Department of Chemistry, mihalick@uwosh.edu

${ }^{3}$ University of Wisconsin-Oshkosh, Department of Educational Leadership and Policy, mogiheiy@uwosh.edu

${ }^{4}$ University of Wisconsin-Oshkosh, Department of Educational Leadership and Policy, parks@uwosh.edu

${ }^{5}$ University of Wisconsin-Oshkosh, Department of Sociology, vanaukep@ uwosh.edu
} 
of the obstacles individual instructors face in implementing changes to their courses. Amundsen and Wilson (2012) note, "At this point in time, we know more about how to design educational development initiatives to improve individual teaching practice but less about how this learning is actualized and embedded in the academic workplace" (p. 111).

\section{Encouraging Pedagogical Change}

One of the difficulties faced by many college and university instructors is that they have little to no background in teaching strategies. Knobloch and Ball (2006) suggest, "Few professors have actually been taught how students learn and how to best teach their students" (p. 4). This is perhaps especially true of culturally responsive teaching strategies. In fact, many professors have learned their teaching strategies by observing their own college instructors' use of direct instruction centered in a teacher led model. Demir, Sutton-Brown, and Czerniak (2012) writing about science and mathematics professors in particular, argue faculty are often not equipped to be critical about their teaching because, unlike their colleagues in elementary and secondary education, most have no formal preparation for teaching. Mostly, they rely on their past experience in the way they were taught ... and college-level teaching becomes on-the-job training taking place without help and resources (p. 1070).

Barr and Tagg (1995) argue that the switch to learner-centered pedagogy requires a complete paradigm shift from an "Instruction" paradigm to a "Learning" paradigm. In this change process, instructors take on the role of both teachers and learners which often requires a major reconceptualization of teaching and learning. Such a transformation requires increased knowledge of teaching strategies, desire to change, and willingness to put more time and energy into teaching (Knobloch \& Ball, 2006).

Often the faculty development process is initiated by a workshop in which instructors learn about new teaching strategies; however it is clear that workshop participants are not always able to execute recommended instructional changes (Amundsen \& Wilson, 2012). In fact, such programs can increase the number of faculty who initially try new teaching strategies, but many who begin to use these strategies during these implementation efforts cease using them soon afterwards. In their survey of 722 physics instructors, Henderson, Dancy, and NiewiadomskaBugaj (2012) found that approximately one-third of faculty discontinued using research-based instructional strategies after trying them for the first time. Glowacki-Dudka, Murray, and Concepcion (2012) found that a workshop series on inclusive pedagogy inspired some instructors to change their courses. They also argued, however, that for ongoing instructor learning, instructors could benefit from more opportunities for group reflection and dialogue about their course changes. One such faculty learning community, which met biweekly for an extended period of time, resulted in implementation of pedagogical changes that were highly rated by a diverse group of students and may also have increased student success (Smith et al., 2008).

The role of reflection and dialogue is especially important when the pedagogical change being sought is increased use of culturally responsive pedagogies. A major goal of culturally responsive pedagogy is not only to affirm cultural identities but also to help develop critical perspectives that challenge the inequities schools and other institutions perpetuate (LadsonBillings, 1999). In order to develop critical perspectives in students, instructors need to adopt critical perspectives themselves. Richards, Brown, and Forde (2007) note "by honestly examining their attitudes and beliefs about themselves and others, teachers begin to discover why they are who they are, and can confront biases that have influenced their value system" (p. 65). Through this reflective process, teachers learn how to determine the multicultural strengths and 
weaknesses of curriculum designs and instructional materials and make the changes necessary to improve their overall quality (Gay, 2000).

Previous research suggests that in order to promote long term changes in instructional practices, faculty development strategies should involve more than just a one-time workshop; rather, they should be longer term, at least one semester (Henderson, Beach, \& Finkelstein, 2011), encourage instructor reflection and coherence with instructor teaching philosophy and beliefs (Richards, Brown, \& Forde, 2007), and include institutional support (Demir et al., 2012). In this paper, we report on an initiative that featured all of these components and explore the following research question: what is the experience of instructors changing their courses to create a more culturally responsive classroom? Exploring these experiences using research based practices for faculty development can help us to understand how to encourage the transformation required for meaningful adoption of culturally responsive pedagogies.

\section{Research Methodology}

\section{Participants in the Gateway Success Faculty Development Process}

Recognizing that the change process often begins when a desire for change meets new knowledge, our university has developed its own "Gateway Success" initiative which educates instructors about the unique challenges faced by diverse students in introductory (or gateway) courses and encourages them to adapt their pedagogy accordingly. As part of this initiative, a two day workshop on inclusive teaching strategies and student success was offered for instructors who were interested in making changes to their courses to better serve diverse students. During the workshop, instructors participated in discussions of inequities experienced by first generation and minority students, read about high impact practices, and developed action plans for their courses. The instructors had to agree to make a significant change to increase the success of diverse students in their course over the year following the workshop, and were provided a $\$ 500$ stipend for doing so. Although this was a moderate stipend, it acknowledged the time and energy needed to make such changes in the course. This type of institutional recognition for the challenges inherent in making course changes is an important part of increasing the use of culturally responsive pedagogies (Demir et al., 2012).

Following the gateway success workshop, instructors were recruited for this study via e-mail and all agreed to participate. The seven instructors in the study taught in the areas of English, History, and Psychology. All were experienced instructors with several years of teaching experience. Instructors of both small (25 students) and large (100-250 students) gateway courses were included in the sample.

\section{Data Collection}

All research procedures were reviewed by the university's review board for protection of human subjects. In order to encourage reflection and continuous learning, the project used the instructors' action plans, structured reflections, in-depth interviews, classroom observations, and discussions within a learning community of instructors before, during, and after instructor interventions. Each instructor participated in an interview (average length of 45 minutes) before the semester began where they discussed goals and expectations for their courses. During the semester, peer observations by researchers were conducted to observe how the instructors were incorporating pedagogical and/or curricular changes in the classrooms. At the end of the 
semester, instructors were interviewed about their learning processes and the results of course changes (average length of 30 minutes). In addition, most of the instructors also participated in at least one focus group (one held mid-semester, one held post-semester) about their experiences. During interviews, instructors were asked to describe the following: their confidence as an instructor; motivations for changing the course; goals for their changes; plans for, implementation of, and outcomes (areas of difficulty and accomplishments) from the instructional changes.

The interviews and focus group recordings were transcribed for analysis yielding 161 single-spaced pages of transcript. In addition to the transcripts, several additional written documents were reviewed. These included the action plans written at the beginning of the semester detailing course changes and a summary of the researchers' peer observations. Some instructors also submitted periodic written reflections on their course changes.

All transcripts and action plans were uploaded into Atlas.ti, a qualitative software analysis program. This program was used to sort, separate, and categorize the various data sources using the constant comparative method of data analysis (Strauss \& Corbin, 1990). This initial analysis revealed that although instructors used a wide variety of teaching strategies to make their classes more inclusive (11 emerged from our initial coding), the process of changing the courses generated both challenges and successes. To interrogate these challenges and successes in more depth, the data were subdivided and each research team member independently reviewed two interview transcripts focusing on the three key challenges found in the data. Notes were made on the major subcategories associated with the primary challenges and then discussed by the group.

\section{Results and Discussion}

\section{Pedagogical changes}

The action plans showed that the workshop inspired the instructors to use a wide variety of strategies in an effort to make their classes more inclusive and increase their alignment with culturally responsive pedagogy. Examples are listed in Table 1. All of these pedagogical changes were undertaken with the goal of making students feel more accepted in the classroom

Table 1

Pedagogical strategies used by participants

\begin{tabular}{ll}
\hline Aspect of course & Examples \\
\hline instructor-student interaction & holding individual meetings with students \\
& providing more frequent feedback to students \\
\hline content & materials expressing a wide variety of perspectives \\
& explicit discussion of issues of diversity and white privilege \\
& encouraging students to make connections between courses \\
\hline classroom activities & taking attendance \\
& introductory icebreaker activities \\
& collaborative learning assignments \\
& clicker questions \\
& student led discussions \\
& written reflections \\
\hline
\end{tabular}


and increasing student achievement. Data collected to measure the effect of the pedagogical changes upon the students found a decrease in failing and withdrawal rates in the larger courses, and a very positive perception of classroom climate in the smaller courses, suggesting that the changes were at least somewhat successful in meeting the stated goals of the instructors.

\section{Challenges and Successes}

The analysis revealed that regardless of class size, instructor experience, or course content, instructors all experienced similar challenges and successes related to incorporating more culturally responsive and learner-centered pedagogy. These appear in Table 2. The interviews and focus group exposed difficulties faced by instructors and allowed discussion of these challenges and their management skills. In short, these conversations provided a more comprehensive understanding for the implementation process in the "academic and social context" where faculty actually work (Amundsen \& Wilson, 2012, p. 111).

Table 2

Common experiences during course transformation process

\begin{tabular}{ll}
\hline Type of experience & Examples \\
\hline challenging tasks & $\begin{array}{l}\text { incorporating/representing multiple perspectives } \\
\text { facilitating discussions } \\
\text { assessing student work }\end{array}$ \\
\hline enabling factors & $\begin{array}{l}\text { instructors viewed themselves as students } \\
\text { embraced developmental perspective of change } \\
\text { support from other members of learning community }\end{array}$ \\
\hline
\end{tabular}

Despite significant obstacles to course transformation, all instructors felt positively about the Gateway Success faculty development process. They had increased their knowledge of students' backgrounds and cultures, which is a fundamental first step to implementing culturally responsive pedagogy (Adams, 1992). They had also adopted more critical perspectives of their own teaching practices, attitudes, and beliefs which will enable them to confront and continue to challenge their own biases (Gay, 2000; Richards, Brown, \& Forde, 2007). Furthermore, instructors were committed to continuing to implement changes to transform their teaching. Instructors' comments also suggested two common reasons for their perseverance: (1) they viewed themselves as students and embraced a developmental perspective of change, and (2) they felt supported by other members of the learning community.

\section{Multiple Perspectives}

In her article "Promoting Diversity in College Classrooms: Innovative Responses for the Curriculum, Faculty, and Institutions" (1992), Adams acknowledges four dimensions of teaching and learning that are central to issues of social and cultural diversity. The first of the dimensions is: Knowing one's students and understanding the ways students from various social and cultural background experiences the classroom (p. 10.) A key finding in this research was that the training workshop in culturally responsive pedagogy led to an increase in instructor awareness of the varied backgrounds and cultures of their students.

Study participants learned that engaging students where they are is key to creating an 
environment of respect and learning. Instructor comments highlighting this included, "Being more sensitive to the fact that what I'm seeing may not be the whole picture," "I want to make everything more clear in the beginning of class, and discussions about being more respectful about other people's opinions," and "I want to help those [white] students while also making sure that people of color feel welcome to say things and say hey, this is my reality, even though it's not representative of everyone." A challenge all instructors faced is students do not all come to university with the same level of preparedness. Since "some have better skills than others" there are students who need more support. The appreciation for these varied perspectives led instructors to struggle both with how to incorporate these perspectives into the class and design times to meet with students to expand their understanding of student perspectives.

One instructor noted his struggle with understanding the perspective of students from other cultures and how to incorporate that perspective into the class. This instructor states:

It's still hard for me to figure out how a minority student might perceive the history that we're talking about. In particular, well, when we talk about the history of slavery, I would think that this is just a difficult subject to talk about and in my experience, most African American students kind of clam up more than usual when that topic comes up...Also, Native American students. You know, this is early American history, so we talk a good deal about English/Native or U.S./Native encounters, and so I really don't know how Native students perceive this and how it feels.

As instructors became more aware of the need for culturally responsive pedagogy, they simultaneously became aware of their lack of expertise and training in presenting multiple perspectives on issues. One instructor noted, "I have a gender class right now and I always feel like I am letting somebody down. Am I representing this position well enough? It does feel somewhat overwhelming."

In response to their new insights, our instructors adopted several teaching strategies to increase students' likelihood for success. For example, instructors attempted to select materials and represent diverse positions to increase the students' ability to relate and/or connect with the course. Selecting new culturally appropriate materials proved difficult, particularly as instructors had little training in culturally responsive pedagogy or culturally inclusive materials. One literature instructor noted:

I thought well, who am I to bring diversity into the classroom? There is so much to cover but, yeah, I was overwhelmed with what should I do...And then there are always new things out there so that's exciting but overwhelming.

In some cases, when appropriate texts were known and available, providing them was cost prohibitive for students. An introductory writing instructor stated, "Basic writing textbooks cannot be had for under $\$ 75$. At-risk students are asked to pay $\$ 75$ for a textbook...I think it's ridiculous, so I did away with the textbook and found stuff online that I thought would work." Although this strategy was helpful for the students, finding and selecting an entire semester's worth of materials proved an enormous time commitment for the instructor.

Another strategy adopted by several instructors to meet the needs of the students and increase the instructors understanding of the student perspective was to hold one-to-one meetings with students. Several instructors who incorporated individual meetings with students found them to be successful in building relationships with the students, but taxing on the instructor. One instructor noted, "Obviously I got to know them very well because I saw them in these tiny classes and then met them outside of classes like eight times, but that was too much. I need to change that a little bit." Instructors in both large and small classes were overwhelmed by the 
amount of time it takes to engage the students they were concerned about and adapt the class to meet such varied student needs.

In addition to the time required outside of class, some instructors struggled with managing time inside the classroom. This time challenge is exacerbated with culturally responsive pedagogy because the interactive teaching required for a culturally responsive classroom can significantly increase the amount of time needed inside and outside of class beyond a traditional lecture based course delivery. The amount of time scheduled for a class is finite, and many of our instructors voiced concerns about scaling down their lecture time for more in-class writing and discussion. An instructor working with a large class stated, "The problem that I've had actually as long as I've done this assignment has been my own time management; making sure that they get a really solid chunk of discussion time in." While classroom discussion was viewed as a critical strategy for culturally responsive pedagogy, instructors reported struggling with more than just managing time when it came to classroom discussions and debate.

\section{Classroom Discussion}

Even when instructors felt they had been more successful in bringing diverse perspectives and materials to the students, they struggled with the ability to guide class discussions about culturally sensitive issues. When asked about the challenges faced in being more inclusive in the classroom, one instructor (a white woman who teaches African American literature) began by noting her own insecurities. She states:

Do I have a right to talk about this? If I open up some time of dialogue am I going to be strong enough to control it, am I going to have enough empathy to handle the situation, you know compassion where necessary...I want to make sure a student doesn't feel shut down for the rest of the semester because of something that happened. Or something happens how can I make you feel comfortable again? How can I make each student feel safe to give his or her opinion?

While this instructor with an advanced degree in African American literature could be considered an expert in the subject area, an introduction to culturally responsive pedagogy increased her awareness of the variety of perspectives on any given topic and made her feel like a novice. Although it could be argued this increased appreciation for multiple perspectives makes this instructor a better and more culturally responsive teacher, it would be remiss to not also appreciate the increased stress and workload the instructor experiences as she attempts to present and balance the representation of multiple perspectives in the classroom.

Instructors reported that they were not alone in their reticence about classroom discussions on culturally sensitive issues; students also seemed to be reluctant to engage in discussions. When issues that involved race were part of the readings or the discussions, instructors were often met by silence. "I was unsuccessful in getting some of those quiet students to speak up." Others experienced direct resistance to the topics, "Eye-rolling, sitting there, who cares about this."

Instructors observed in some white students a feeling that since the subject was now about race they no longer had to participate. They became disengaged or turned to the students of color in the room and waited for them to answer. Instructors became frustrated with white students who did not appear to think issues of race were something they should be a part of; "You have students who are calling people "colored people" in the same class, so, on one hand, it's not their responsibility to educate anyone, but on the other hand, there's some people who 
really need to be educated."

Instructors were aware many students of color did not participate in the discussions once the discussions turned to race because they did not want to be the "token:"

It's my impression that a lot of African American students....don't really want to engage these issues in the classroom and don't particularly feel comfortable talking about them and, no I'm not [asking them], "So, what is the black perspective on this?"

Instructors also discovered that when discussions did actively engage students in controversial issues, there was often such obvious disagreement from the white students and the students of color that instead of improving the classroom dynamics, the discussions increased the feeling of needing to tiptoe around issues. One person gave an example of a heated discussion by a white student and an African American student on the topic of "driving while black." The instructor was not certain how to handle the intense emotions arising out of the conversation so the fallback was to stop it:

...the African American student was very vocal and was great about giving opinions so it was a wonderful experience, but then there was another student who said something where he's like, "I don't believe this exists" and things like that, and I tried to jump in and steer it around but the damage had already been done.

Instructors reported they struggled to find, connect with and maintain a relationship with students, especially those students of color struggling in classes. One instructor noted, "For example, the student almost always arrives late." This instructor continued to talk about attempts with this one student, "We have met on many occasions and both he and I are honestly concerned about how well he's going to do in this class...I don't know what else to do." There was frustration at the inability to break up groups of students in the classroom; "even in my class, that is incredibly diverse, I see clumping; [they] just fight what I do... White students, they clump by geography," and "There are rural students and the urban students and they just gravitate toward each other. No matter what I do to get them together, they go back to the spots."

\section{Assessment of Student Work}

This increased appreciation of multiple perspectives also suggests an increased awareness about diversity in the manner in which students might demonstrate their learning. As instructors began to evaluate the outcomes of their pedagogical changes, it became clear they were forced to reevaluate their definitions of success and their assessment strategies. Based on literature reviewed in the initial workshop, some instructors made changes in their courses such as breaking projects into smaller pieces and building student reflection components into the course. Although these strategies were incorporated to increase student success and often did, some instructors were left wondering if such changes made their classes too "easy" and reflected a lowering of standards.

One instructor wrestled with this dilemma when asked about the success of the pedagogical changes:

It's a little bit hard to say only because this was such an outstanding group. I'm reluctant

to put their success onto the changes that I made. I'm sure they had something to do with it, but it was one of the best...groups that I have ever had... In fact, I felt I need to grade harder. I think 22 out of 23 got a $\mathrm{C}+$ or higher.

Although the fact that this number of students got a $\mathrm{C}+$ or higher appeared to be a success, this instructor was clearly struggling with this outcome. Instead of praising the new pedagogical strategies and the increased learning of the students, the instructor wondered if he had high 
enough grading standards:

I've always felt like, jeez, if there aren't a substantial handful getting C's and D's, maybe the project's not hard enough. It is hard enough and I guess I just have to say this group was just so good that they all earned it. They did everything I asked them to do. I'm comfortable with their research, I'm comfortable with their writing ability, I'm comfortable with their thinking ability and the fact that the vast majority of them got a B or above is just due to them. It's not like I've got to go back and make the project harder, because it was a lot of work.

In this quotation one can witness the instructor wrestling with the old expectation that only some students should succeed and with a new understanding that, given the right coaching and environment, any student can succeed. An increased student success ratio does not necessarily mean standards have been lowered, but could also mean that new strategies raised students up to the level of previous standards.

The challenges the instructors faced led them to make changes in their assignments and assessments as well as in their attitudes towards working with students. There was a consistent feeling this did not require them to lower standards in any way; rather, they tried to negotiate other ways to approach the material for increased student success. Some of the changes were academic in nature and required the teacher to adjust reading assignments or pedagogical approaches to the material, "I would cut back on the amount of reading because it is not important that you read 4-6 essays... it is more important that you get it." Another instructor shared:

One thing I learned is that they really suck at summarizing and paraphrasing because they are not careful readers and writers, So instead of having them read things that they are going to summarize and paraphrase a.k.a. copy and paste, we are going to watch them on TV or listen to them on tapes.

In sum, the Gateway Success Project's transition to a new way of teaching forced instructors to reframe their own teaching identities, change their teaching practices and challenge some of their assumptions about their role in the classroom. Instructors struggled with the alignment between their own behaviors, classroom modifications and their understandings of themselves as teachers. What had once been a position of expertise and authority is now a position of learning, questioning, and experimenting. While these instructors were eager to change their courses, embrace a new self-concept, and experiment with new strategies, they also experienced stress and uncertainty during the process. However, they also all expressed plans to use these strategies and other culturally responsive strategies in the future.

\section{Learning Opportunities}

In reflecting upon courses at the end of the semester, most of the instructors felt they had progressed in making their classes more inclusive, but had not yet perfected their classes. Instead of reporting upon this as problem, instructors viewed these challenges as learning opportunities. One instructor stated, "I had to tweak some things for spring semester just in terms of clarifying some stuff, questions that came up."

Instructors in our study embraced the learning paradigm (Barr \& Tagg, 1995) for themselves and their students. In their provocative essay proposing a new paradigm for higher education, Barr and Tagg (1995) note the role of instructors will undergo a fundamental change when challenged with integrating culturally responsive pedagogy into their classroom. Instructors must transition from the role of "expert" teachers who impart knowledge to the role 
of "coaches" who create and moderate learning environments in which teacher and student exchange the role of expert and novice. If instructors were supposed to be experts in teaching as well as in their content material (Barr \& Tagg, 1995), they would be discouraged by their experiences with culturally responsive pedagogy. However, the reverse was often true. By positioning themselves as co-partners with students in this process of learning, instructors normalized challenges and failures as part of the learning process and were excited about the small successes experienced along the way. One instructor explained:

It will be fascinating to see how we all came into it and looking back at how naïve we were. But that is part of our process. That whole process of learning, that stage is a part of it...that scary stage like am I ever going to get this? The ones who have been teaching it longer seem more relaxed with it so that gives me hope.

This instructor's hope seems to come from two sources - the embracing of the process model of learning and the experiences of other colleagues.

As suggested by previous research (Glowacki-Dudka et al., 2012), the faculty learning community was very helpful for these instructors. In this study, all of the instructors were able to connect in a large group setting during the initial training session and again during the focus groups. In addition, the instructors were also able to connect with the researchers throughout the time period of the project. This social support served three primary purposes: normalizing of experiences, provision of resources, and accountability for reflection.

When instructors met with one another in the group setting, they were able to share their experiences in the classroom. Because instructors traditionally work alone, the life of a teacher can be very isolating. One instructor reflected, "I always think about teaching as being very solitary. So well I mean that's just how it's always been. You know, I was given textbooks and was told 'here, get out there.' " Participating in the learning community allowed members to break out of that isolation and share their experiences with one another. The net result of this sharing was instructors realized the challenges they were experiencing were also being experienced across the university. During the focus group, one instructor explained her thoughts, "Are my students reacting this way because I'm the only person asking them to make connections in this way? So, they think that I'm just like a space alien and not someone who's challenging them to think?" By attending these workshops, the instructor was able to normalize her experiences and build connection with other instructors.

Reflecting on the focus group, another instructor stated:

One of the things I enjoyed or took out of it most is seeing how many other faculty members were interested in the same issue. So I think knowing that there's that support there and that there are other people who share the same interests and goals was important.

These connections also served as a source of resources and ideas for teaching. One instructor explained, "I would love to get together again as a group. I wish more people could have come to the small group thing because I want to know more about what other people are doing." During the workshop, focus group, and interviews, instructors were able to share ideas and resources. For example, when one instructor would wonder what to assign for a reading, another instructor would suggest a possible choice. Assignment struggles could be detailed and possible alternatives brainstormed.

Finally, the interviews and interactions with others in the learning community encouraged instructors to reflect upon the changes in their classrooms and what they were learning. Although all of the instructors believed reflection is an important part of learning (Schon, 1983) and many 
assigned reflection activities to their students, actually taking time to reflect upon their own learning is always a challenge. Hence, one of the important functions of a learning community is to hold one another accountable for being reflective practitioners. One participant noted:

At a bare minimum, forcing me to sit down and reflect on the questions helped me to see the forest (vs. the trees). The interviews (and accompanying questions) allowed me to pause and consider the impact of the changes I was making beyond just logistics. Perhaps more importantly, I made changes to the assignments in response to my reflections. For example, after reflecting that students probably weren't getting enough time to do some of the mini-writings, I started moving them to the middle of the lecture instead of the end. I also changed the instructions and structure of some of the mini-writings as a result of the reflective process. I suppose it might also be worth saying that I found the interviews and reflections to be support-building. It reminded me that I was part of a bigger team of instructors making these changes and that others thought the work I was doing was important. This was particularly helpful in the middle of the semester as I found myself overwhelmed with classes and other projects.

Some of the beneficial aspects of this learning community have also been reported in studies of other institutions. A survey of people at 132 institutions on the impact of faculty learning communities on incorporating diversity into teaching found that participants gained an understanding of student learning differences, and learned how to consider the variety of needs of their students when planning and implementing courses (Petrone, 2004). Researchers at Miami University observed that "an FLC on diversity must operate on both emotional and intellectual levels" (p. 116), but no mention is made of whether the community continued meeting through the implementation phase, when our study's participants especially appreciated peer feedback and support.

\section{Conclusions}

Research has found that beyond disseminating knowledge of a new teaching method, the following three strategies have been important in achieving effective use of the method: focusing on it over a period of time (a month, semester or year) rather than in a one-day workshop; providing performance evaluation, feedback or coaching to the instructors while they are trying the new method; and focusing on changing faculty conceptions of their students and themselves (Henderson, Beach \& Finkelstein, 2011). The Gateway Success Faculty Development Process met these criteria and resulted in several indicators of success, while a similar project at a different institution with the same goal of promoting inclusive pedagogy had a smaller fraction of participants who actually attempted new pedagogical strategies. Analysis of this comparison project hypothesized that periodic opportunities for group discussion and reflection on the process would have resulted in continued improvements in teaching (GlowackiDudka et al., 2012).

This study explored the experiences of instructors changing their courses to create a more culturally responsive classroom. While the transformation process was a very challenging one for instructors, several enabling factors, many supported by previous research, encouraged success and a continuing commitment to transformation. Our study supports the idea that the implementation of learner-centered, culturally responsive pedagogies benefits from ongoing social support and time for instructor reflection as instructors deal with numerous potential challenges to transforming their teaching. These challenges might emerge from: 1) time constraints; 2) lack of confidence in trying new methods; 3) confronting their own cultural 
insensitivity; and 4) dealing with the resulting emotions. All study participants encountered such difficulties but nonetheless expressed plans to use learner-centered methods and culturally responsive strategies in the future.

These findings suggest that higher education institutions looking to create more inclusive environments might consider the use of learning communities, which can provide instructors with a forum to discuss their experiences, help to normalize the challenges they encounter, and offer support for small victories on the path towards transformation of their pedagogy. Future research should continue to explore the links between faculty learning communities and successful teacher development. In addition, institutions could use this study to give new instructors, and instructors trying new teaching methods, a more realistic preview of the current higher education environment. If instructors understand that challenges like those encountered by our Gateway Success participants are a normal part of their job, and they embrace failure and partial success as necessary to teacher development, it may help to decrease teacher burnout and turnover (Miller, 2012) and simultaneously increase student success.

\section{References}

Adams, M. (1992). Promoting diversity in college classrooms: Innovative responses for the curriculum, faculty, and institutions. San Francisco: Jossey-Bass.

Amundsen, C., \& Wilson, M. (2012). Are we asking the right questions? A conceptual review of the educational development literature in higher education. Review of Educational Research, 82(1), 90-126. dio: 10.3102/0034654312438409

Barr, R.B., \& Tagg, J. (1995). From teaching to learning: A new paradigm for undergraduate education. Change, 27(6), 12-26. doi: 10.1080/00091383.1995.10544672

Cooper, M. A. (2010). Investing in education and equity: Our nation's best future. Diversity and Democracy, 13(3), 1-4.

Demir, K., Sutton-Brown, C., \& Czerniak, C. (2012). Constraints to changing pedagogical practices in higher education: An example from Japanese lesson study. International Journal of Science Education, 34(11), 1709-1739. doi: 10.1080/09500693.2011.645514

Gay, G. (2000). Culturally responsive teaching: Theory, research, and practice. New York: Teachers College Press.

Glowacki-Dudka, M., Murray, J. \& Concepcion, D.W. (2012). Reflections on a teaching commons regarding diversity and inclusive pedagogy. International Journal for the Scholarship of Teaching and Learning, 6, 1-13.

Henderson, C., Beach, A. \& Finkelstein, N. (2011). Facilitating change in undergraduate STEM instructional practices: An analytic review of the literature. Journal of Research in Science Teaching, 48(8), 952-984. doi: 10.1002/tea.20439

Henderson, C., Dancy, M., \& Niewiadomska-Bugaj, M. (2012). Use of research-based instructional strategies in introductory physics: Where do faculty leave the innovation-decision 
process? Physical Review Special Topics - Physics Educational Research, 8, 020104. doi: 10.1103/PhysRevSTPER.8.020104

Knobloch, N.A., \& Ball, A.L. (2006, April). Analyzing the contextual, motivational, and conceptual characteristics of teaching faculty in regard to the use of learner centered approaches to teaching. Paper presented at the meeting of the American Education Research Association, San Francisco, CA.

Ladson-Billings, G. (1999). Toward a theory of culturally relevant pedagogy. American Educational Research Journal, 32(3), 465-491. doi: 10.3102/00028312032003465

Miller, K. I. (2012). Organizational communication: Approaches and processes. Boston, MA: Wadsworth.

Nelson, C. E. (1996). Student diversity requires different approaches to college teaching, even in math and science. American Behavioral Scientist, 40(2), 165-175. doi:

10.1177/0002764296040002007

Petrone, M. C. (2004). Supporting diversity with faculty learning communities: Teaching and learning across boundaries. New Directions for Teaching \& Learning, 97, 111-125. doi: $10.1002 / \mathrm{tl} .138$

Richards, H., Brown, A., \& Forde, T. (2007). Addressing diversity in schools: Culturally responsive pedagogy. TEACHING Exceptional Children, 39(3), 64-68.

Schon, D. A. (1983). The reflective practitioner: How professionals think in action. Farnham, Surrey England: Ashgate Publishing Limited.

Sleeter, C. (2012). Confronting the marginalization of culturally responsive pedagogy. Urban Education, 43(2), 562-584. doi: 10.1177/0042085911431472

Smith, T. R., McGowan, J., Allen, A. R., Johnson, W. D., II, Dickson, L. A., Jr., Najee-ullah, M. A., \& Peters, M. (2008). Evaluating the impact of a faculty learning community on STEM teaching and learning. The Journal of Negro Education, 77(3), 203-226.

Steele, C. (2010). Whistling Vivaldi: How stereotypes affect us and what we can do. New York: W.W. Norton \& Company.

Strauss, A., \& Corbin, J. (1990). Basics of qualitative research: Grounded theory procedures and techniques. Newbury Park, CA: Sage Publications, Inc. 